\title{
Consumo e subjetividade: trajetórias teóricas
}

\author{
Deise Mancebo \\ Dayse Marie Oliveira \\ Jorge Guilherme Teixeira da Fonseca \\ Luciana Vanzan da Silva \\ Universidade do Estado do Rio de Janeiro
}

\begin{abstract}
Resumo
Considerando o consumo como o conjunto de processos socioculturais nos quais se realizam a apropriação e os usos dos produtos, este artigo tem por proposta uma análise histórica das principais teorizações sobre esta temática, com destaque às análises que se preocuparam com efeitos de subjetivação advindos da "sociedade de consumo". Apresenta e analisa as primeiras contribuições para esta discussão em Marx e em alguns autores da Escola de Frankfurt; discute os desenvolvimentos teóricos que buscam na Semiologia um apoio para a compreensão do comportamento consumista e finaliza com a apresentação e análise de algumas teorizações que tomaram a temática no contexto da globalização. O artigo conclui destacando a importância da continuidade dos estudos sobre a temática, que considerem as suas múltiplas facetas - econômicas, políticas, históricas, sociais, culturais e psicológicas - e que relevem, no exame empírico, a concreticidade de espaços sociais específicos.

Palavras-chave: Consumo, Subjetividade, Cultura, Globalização.
\end{abstract}

\begin{abstract}
Consumption and subjectivity: A theoretical analysis Considering the consumption as a set of sociocultural processes in which the appropriation and the uses of the products take place, this article proposes a historical analysis of the main theories about this topic, emphasizing the analysis that examined the effects of subjectivity on the "consumer society". It presents and analyzes the first contributions for this discussion in Marx and in some authors from the Frankfurt School; it discusses the theoretical developments that borrow from Semiology a support for the understanding of the consumption behavior and it concludes with the presentation and analysis of some theories that consider the topic in the global context. The paper concludes with an exam of the importance of further studies about consumption, considering its multiple interfaces, economical, political, historical, social, cultural and psychological, and that raise, in the empiric exam, the concrete aspect of specific social spaces.
\end{abstract}

Key words: Consumption, Subjectivity, Culture, Globalization.

$\mathrm{O}$ estudo do consumo - aqui entendido como "o conjunto de processos socioculturais nos quais se realizam a apropriação e os usos dos produtos" (Canclini, 1999, p. 77) - , da cultura de consumo e até da sociedade de consumo só se tornou uma área conceitual de importância para as ciências sociais e humanas recentemente. As profundas transformações a que assistimos nos últimos anos - as transações de mercado operadas pelas grandes corporações, as novas características de "acumulação flexível do capital" (Harvey, 1994), os meios de comunicação de massa, a propaganda subliminar a nos convencer a incorporar novos conceitos sobre as nossas necessidades, mas também as propensões sociais e psicológicas, como o individualismo e o impulso de realização pessoal por meio da auto- expressão, a busca de segurança e identificações coletivas todas estas questões, tão presentes no cotidiano global, levaram a que disciplinas sociais e humanas passassem a se debruçar sobre os modos de consumo e estilos de vida de maneira mais intensa, retirando a questão de um certo submundo acadêmico.

No entanto, mesmo que de forma secundária e marginal, o consumo tem sido motivo de análises pelo menos desde o século XIX, e o consumismo, em especial nos países ricos, constituiu-se em alvo de críticas mais intensas e freqüentes, desde os anos 60 do século que acaba de findar. Este texto propõe-se exatamente a retomar algumas destas teorizações sobre a temática, finalizando, no entanto, com a análise do comportamento consumista no contexto global. 


\section{As primeiras análises: a teoria crítica sobre o consumo}

Marx é a referência clássica para este percurso que nos propomos. Viveu no início da sociedade industrial e já apontava algumas de suas principais características. Sua teoria sobre o consumo permite-nos desenvolver dois conceitos, recorrentes em outros autores que lhe seguiram: a alienação e a opressão. Estes dois conceitos são inicialmente desenvolvidos na sua teoria sobre o fetichismo da mercadoria que poderíamos assim sintetizar: a mercadoria é uma ilusão sobre o produto, forjada pelo capitalismo.

Conforme sua análise, é a necessidade que leva o homem a modificar os elementos naturais, atribuindo-lhes novas formas. No estágio cultural mais simples, o homem cria o produto, como o resultado direto do dispêndio de sua força de trabalho. Num estágio cultural mais complexo, no entanto, ele cria a mercadoria, misteriosa em sua origem e atiçadora do desejo humano. A forma social do trabalho, o modo como os homens trabalham uns para os outros é o que dá origem ao mistério e forma à mercadoria. Sinteticamente, a exposição marxiana é a seguinte: primeiro, o valor é determinado pelo dispêndio de força humana de trabalho e de quantidade de trabalho — ambos realizados individualmente —; segundo, como os homens trabalham uns para os outros, cria-se uma relação social do trabalho; terceiro, essa relação é, então, disfarçada numa relação entre produtos do trabalho.

Quando se nega a existência da relação social do trabalho humano e se passa a tomá-la como uma relação material inerente ao produto, transforma-se o produto em mercadoria. O produto, então, perde sua relação com o trabalho humano, passa a ser considerado uma relação entre coisas; relação esta que cresce até se tornar uma abstração, a reger o valor da mercadoria. Na expressão do próprio Marx (1867/1980):

Uma relação social definida, estabelecida entre homens, assume a forma fantasmagórica de uma relação entre coisas. (...) É o que acontece com os produtos da mão humana, no mundo das mercadorias. Chamo a isto de fetichismo, que está sempre grudado aos produtos do trabalho, quando são gerados como mercadorias (Marx, 1867/1980, p. 81).

Deste modo, para os consumidores, não há relação direta entre os indivíduos e seus trabalhos, ou seja, para eles trata-se da mera compra de uma mercadoria - o produto imediato que tem nas mãos. Mesmo sabendo da proveniência do produto, não vêem a relação material e social entre o produtor e o produto. Assim, a expansão desse tipo de transação fez com que os homens produzissem diretamente para fins de troca, considerando o valor dos bens especialmente sob esta faceta.

Para Marx, portanto, o que determina, na prática, o valor da mercadoria é a proporção de mercadorias que se pode conseguir com uma outra mercadoria. "Fórmulas que pertencem, claramente, a uma formação social em que o processo de produção domina o homem e não o homem o processo de produção, são consideradas, pela consciência burguesa, uma necessidade tão natural quanto o próprio trabalho produtivo" (Marx, 1867/1980, p. 90). Esse naturalismo econômico é uma ilusão que o fetichismo da mercadoria constrói na mente burguesa, resultando que o valor das mercadorias seja apenas determinado pela quantidade proporcional de dinheiro na troca. "É, porém, essa forma acabada do mundo das mercadorias, a forma dinheiro, que realmente dissimula o caráter social dos trabalhos privados, e, em consequiência, as relações sociais entre os produtores particulares, ao invés de pôlas em evidência" (Marx, 1867/1980, p. 84).

A alienação dos consumidores em relação à verdadeira natureza do objeto que consomem abre as portas para uma alienação mais profunda, a da naturalização das relações sociais de produção e de trabalho, de modo que o encobrimento da realidade social do produto serve à exploração das forças de trabalho que o produziram. $\mathrm{O}$ resultado desse processo, portanto, é a opressão das massas consumidoras, mas também e, principalmente, das massas trabalhadoras.

Os primeiros pensadores da Escola de Frankfurt tomaram o pensamento marxista para analisar diversas temáticas que tangenciam a discussão do consumo. Viveram os efeitos iniciais do fordismo ${ }^{1}$, que se apresentava como uma política de controle e gerência do trabalho, mas cujos efeitos sociais tornaram-se bem mais amplos. Ao tempo das primeiras produções frankfurtianas tomava corpo uma nova estética e uma nova "psicologia" para a sociedade: a idéia de que a produção de massa deveria significar consumo de massa.

Sob estes impactos, Adorno e Horkheimer (1947/1990) ampliaram os estudos marxistas, especialmente para o âmbito da cultura, incorporando inclusive novos conceitos à discussão, tal como a já consagrada expressão "Indústria Cultural". No texto clássico "A indústria cultural: o iluminismo como mistificação de massa" expõem o caráter opressor da arte quando esta é envolvida com a lógica industrial. Para estes autores, inicialmente, tinha-se um desenvolvimento que primava pela ânsia da pureza da arte burguesa - a arte "séria" - e, como corolário, a segregação das classes inferiores. À classe pobre, presa ao ritmo da sociedade industrial, foi delegada uma arte "leve", cuja função era a de lhe garantir alguma diversão durante as poucas horas de folga do dia. No entanto, para Adorno e Horkheimer (1990), essa divisão entre a arte "séria" e a arte "leve" se dilui no capitalismo tardio, de modo que a "antítese deixa-se conciliar, acolhendo a arte leve na séria e vice-versa" (p.173).

Essa diluição dá origem à cultura de massa - que guarda da arte leve a característica do divertimento e que nasce da massificação da arte erudita - destinada a um público anônimo, formado tanto pelo proletariado quanto pela burguesia. Enquanto no passado, a arte estava intimamente ligada aos grupos sociais da qual se originava - a arte erudita das cortes aristocratas e a arte popular da plebe - no capitalismo tardio, a arte líquida se torna uma força mistificadora da liberdade humana, pois promete liquidificar as classes sociais através do igualitarismo supostamente possibilitado pelo consumo. Mas não liquida as diferenças sociais. A arte líquida, portanto, tem sua gênese no capitalismo tardio, que possui uma imensa capacidade de absorver novos elementos, mas não de mudar suas próprias contradições. 
Para Adorno e Horkheimer (1990), o método de produção da indústria cultural é a repetição, a simplificação e o empobrecimento, reduzindo toda forma de arte a esquemas. A indústria cultural atribui-se, no entanto, a tarefa de ser a nova força civilizadora do homem e passa a controlar a sua vida íntima, através da propaganda de noções vulgares e da venda de imagens. A propaganda, parte orgânica desse processo, visa orientar o consumidor na sua pseudoliberdade de escolha e mais que determinadas mercadorias, vende estilos de vida, narcotiza as consciências, iludindo os homens pelos excessos de imagens. Do torso nu do herói ao tamanho da minissaia da heroína, a indústria cultural reúne a sua mensagem libertária à mensagem da dessublimação do homem. Assim, uma pessoa segue uma rotina determinada pelo seu estilo de vida, na tentativa de se tornar cada vez mais bem sucedida, mais livre, mais feliz, mas nunca alcança a satisfação plena e duradoura. A promessa de dessublimação do homem é uma das estratégias que garantiram a vitória da propaganda, cuja eficiência se constitui na voz dominante dos consumidores. Em outros termos, a indústria cultural constrói seu domínio no homem, através das falsas promessas de dessublimação, contidas nos estilos de vida advogados pela publicidade.

Outro frankfurtiano que contribuiu para a discussão da questão do consumo e da alienação do homem na sociedade industrial, foi Herbert Marcuse. Seus principais textos sobre a questão foram escritos sob o impacto de um consumo de massa já amadurecido, pelo menos nos países capitalistas avançados. O fordismo, como regime de acumulação, alcançara sua plenitude, no pós $2^{\mathrm{a}}$ Guerra, o capitalismo atingira taxas estáveis de crescimento econômico e os padrões de vida se elevaram, em consonância com padrões de consumo mais acelerados. Nesse contexto, Marcuse constrói o conceito de "homem unidimensional", que nos permite discutir os efeitos do comportamento consumista sobre os homens. Este conceito é analisado por Marcuse sob diversos prismas, mas para fins deste trabalho interessa reter que o homem unidimensional é fruto do desenvolvimento de "falsas necessidades", trazidas à vida pela tecnologia.

As criaturas se reconhecem em suas mercadorias; encontram sua alma em seu automóvel, $h i$-fi, casa em patamares, utensílios de cozinha. O próprio mecanismo que ata o indivíduo a sua sociedade mudou, e o controle social está ancorado nas novas necessidades que ela (a sociedade) produziu (Marcuse, 1968, p. $31)$.

Além disso, para Marcuse, o consumismo encobre o conflito entre as necessidades dadas e as necessidades possíveis, criando a falsa noção de igualitarismo através do consumo. Esse falso igualitarismo - na realidade, uma homogeneização para o autor - impede que o homem forme uma visão utópica da sociedade, amortiza seu potencial crítico, de modo que logo, nada o impele à realização de verdadeiras mudanças no mundo.

Assim, para adequar o homem à lógica industrial, as necessidades humanas são manipuladas transformando-se de necessidades sociais em falsas necessidades individuais. A grande velocidade de produção cria a necessidade de um rápido escoamento do consumo, fomenta um forte consumo por parte da população, dando a impressão que, sem este, o sistema ruiria. Por uma construção cultural, o homem unidimensional com suas necessidades pré-determinadas, transforma-se em apenas mais uma peça da maquinaria social, destinada a consumir e consumir. Para Marcuse, a grande necessidade de consumo pode até criar uma euforia, no entanto, esse ânimo é passageiro, restando no final a infelicidade, - nascida de um vazio, construída dentro dele, através da própria lógica industrial, que o impele a consumir mais, formando um ciclo vicioso e gerador das crises existenciais do homem moderno. Em síntese, a alienação manifesta seu caráter opressor através da cultura de massa, cuja espinha dorsal é a naturalização do consumo.

Afirma-se, com os autores frankfurtianos, que a expansão da produção capitalista - especialmente depois do impacto do fordismo e da gerência científica da produção - necessitou da construção de novos mercados e da "educação" das massas consumidoras. A lógica da mercadoria e da racionalidade instrumental invade o consumo, as atividades de lazer, a arte e a cultura, de modo que a recepção cultural é condicionada pelo valor de troca, na mesma medida em que os valores e propósitos mais elevados da cultura sucumbem. A dominância do valor de troca consegue suprimir a memória do valor de uso original dos bens e, assim, as mercadorias ficam livres para associar-se a uma ampla sorte de associações e ilusões culturais, o que é magnificamente bem feito pela propaganda. Estes são motes centrais dos estudos frankfurtianos, ou daquilo que Featherstone (1995) chama de estudos sobre a "produção do consumo".

Atualmente, assiste-se a um interesse cada vez maior pelos estudos da "cultura de consumo", mas não se concebe mais tanta importância aos temas trazidos pela "Teoria Crítica" dos frankfurtianos. Esta abordagem vem sendo apresentada como uma crítica elitista da cultura de massa, apoiada em distinções consideradas discutíveis entre individualidade autêntica e pseudo-individualidade, entre necessidades verdadeiras e falsas, que pouco traduzem as práticas e experiências reais de consumo. De fato, revisitando esta literatura, destaca-se o tom crítico da análise: a indústria cultural desencadeadora do consumo de massa "é uma máquina de imposição da cultura dominante - ideologia dos dominantes, bem entendido - sobre o resto da sociedade" (Rocha, 1995, p. 62). Sob as orientações acima expostas, o consumo é tomado como um momento do ciclo de produção e da reprodução social, o modo como se planifica a distribuição dos bens depende das grandes estruturas de administração do capital, de modo que o tom crítico da análise obnubila a capacidade teórica em examinar processos reais de consumo, que revelam reações e apropriações dos bens muito mais complexas e interativas. No entanto, pode-se argumentar que algumas questões apresentadas pelos proponentes da Teoria Crítica não foram realmente superadas, permanecem questões atuais, não resolvidas inteiramente, especialmente quando se trata da discrimi- 
nação dos valores culturais e dos julgamentos valorativos da cultura de consumo.

\section{Uma análise semiológica sobre o consumo}

Enquanto Marx e os frankfurtianos tratavam da formação da lógica da sociedade industrial e suas conseqüências para o homem, Baudrillard, considerado um pós-marxista, tratará diretamente da sociedade de consumo. Na realidade, ele declara o fim da produção como princípio organizador da sociedade - modelo calcado no sistema industrial de produção de massa, fordista, inaugurado no início do século - e, no seu lugar, considera que os problemas de motivação e promoção do consumo encontram-se em primeiro plano.

Para Baudrillard (1995), a alienação social se dá pela naturalização do consumo, mas o consumo não é de objetos e sim de signos que obedecem a uma lógica própria, de modo que os objetos consumidos deixam totalmente de estar em conexão com qualquer função ou necessidade definida. A mercadoria apresenta-se envolta por características de conforto e bem-estar, passando a dominar o homem, retira-lhe as questões existenciais, para transformá-las em relações associativas e opressivas de signos-objetos, fazendo com que o Ter seja mais importante que o Ser.

Baseado na semiologia, este autor afirma que a lógica social do consumo é estruturada como uma linguagem. Já não se trata da "apropriação individual do valor de uso dos bens e dos serviços; (...) também não é a lógica da satisfação (a que prevalece), mas a lógica da produção e da manipulação dos significantes sociais" (Baudrillard, 1995, p. 59) que é a predominante. O consumo, assim definido, pode ser compreendido como um processo de comunicação - pois a circulação, a apropriação de bens e de signos diferenciadores constituem hoje a nossa linguagem e o nosso código -, mas também como um eficiente processo de classificação e diferenciação social.

É o seguinte o princípio da análise: nunca se consome o objeto em si (no seu valor de uso) - os objetos (no sentido lato) manipulam-se sempre como signos que distinguem o indivíduo, quer filiando-o no próprio grupo tomado como referência ideal, quer demarcando-o do respectivo grupo por referência a um grupo de estatuto superior (Baudrillard, 1995, p. 60).

Mas o consumidor ignora esses processos, de modo que vive as suas condutas consumistas, como distintivas, como sinais de liberdade, de possibilidades de escolhas, e não como um "condicionamento de diferenciação e de obediência a um código" (Baudrillard, 1995, p. 60).

$\mathrm{O}$ consumo remete à noção de abundância e, sob este prisma, os objetos organizam-se de dois modos complementares: a profusão e a panóplia. A profusão, que é a forma mais rudimentar de abundância de objetos e serviços, cria "a evidência do excedente, a negação mágica e definitiva da rareza, a presunção materna e luxuosa da terra da promissão" (Baudrillard, 1995, p.16) e transporta à ilusão de igualdade pelo consumo. O segundo modo de organização é a panóplia, onde os objetos são organizados em coleções, nas quais cada unidade indica uma relação de outros objetos em movimento recíproco. O objeto não é mais consumido como mercadoria, mas como um signo que expressa diferenciações. Assim, quando vemos os diversos modelos de carros, de eletrodomésticos, de móveis etc., a nossa reação psicológica é organizálos numa cadeia de signos que se torna cada vez mais complexa, sugerindo a existência de um superobjeto: um objeto melhor, mais novo, mais apropriado à nossa condição social. Assim, segundo Baudrillard, as estruturas de classes ou grupos são reorganizadas pela panóplia, através da posse de signos-troféus que identificam uma pessoa como membro de uma classe ou grupo. Há, portanto, uma contradição lógica entre profusão - que remete a uma possível equalização do consumo, apresentando muitas mercadorias para todos - e panóplia, por definição, organização dos objetos em coleções diferenciadoras. Na realidade, há "uma contradição lógica entre a hipótese ideológica da sociedade de crescimento (de abundância), que é a homogeneização social no nível mais alto, e a correspondente lógica social concreta baseada na diferenciação estrutural" (Baudrillard, 1995, p. 66).

Em síntese, para o autor, o sistema de consumo não se baseia, em última instância, nem na necessidade, nem no prazer, mas num código de signos e de diferenciações. Deste modo, Baudrillard distancia-se dos autores apresentados anteriormente e chega à conclusão de que "a análise marxiana da produção de mercadorias está ultrapassada, porque o capitalismo agora tem a preocupação predominante com a produção de signos, imagens e sistemas de signos, e não com as próprias mercadorias" (Harvey, 1994, p. 260). O processo de disciplinamento que ocorreu durante o século XIX, no âmbito da produção, alcança seu auge no século XX, no âmbito do consumo. Depois da socialização das massas como força de trabalho, dever-se-ia ir à frente para as socializar como força de consumo, de modo que os anárquicos consumidores do período anterior à $2^{\mathrm{a}}$ Guerra, nada têm a fazer em tal sistema. É neste meandro que se localizam os estudos de Baudrillard: a análise dos "modos de consumo", uma "lógica do consumo, que aponta para os modos socialmente estruturados de usar bens para demarcar relações sociais" (Featherstone, 1995, p. 35), lógica organizada como uma linguagem $^{2}$.

\section{Consumo e diferenciação social}

Outros autores, além de Baudrillard, também se preocuparam com análises sobre a demarcação das relações sociais, que se desenvolvem a partir dos modos de consumo. Um particularmente merece destaque, pois seus estudos já se tornaram clássicos nesta discussão. Trata-se de Bourdieu (1974, 1975), que analisa o consumo como lugar de diferenciação e distinção entre classes e grupos sociais, chamando atenção para os aspectos simbólicos e estéticos da racionalidade consumidora.

Nas sociedades ocidentais contemporâneas, há uma tendência para uma renovação constante das mercadorias oferecidas, dando a ilusão de que o acesso é irrestrito para todos, porém, segundo Bourdieu (1974, 1975), o acúmulo de bens de consumo muito específicos atestam o gosto e a distinção de quem os possui e se constituem num verdadeiro capital cul- 
tural ou simbólico, que não se apresenta em todo e qualquer cidadão. A produção do capital simbólico serve, assim, como um marcador de classe, contribui para a reprodução da ordem estabelecida e para a sua perpetuação; produz formas materiais e concretas de poder; mecanismos nem sempre perceptíveis e não raramente naturalizados. Em decorrência, nas sociedades contemporâneas, boa parte da racionalidade das relações sociais se constrói na disputa pela apropriação dos meios de distinção simbólica, processo imerso nas práticas de consumo.

Como os fluxos de mercadorias são intensos, torna-se difícil uma avaliação do status ou da posição na hierarquia conforme o uso ou porte de determinada mercadoria. É neste contexto que o gosto, o julgamento e o conhecimento das mercadorias assumem importância, auxiliando classes e frações de classe na escolha dos bens, mecanismo que, por seu turno, tem parte ativa na recomposição das hierarquias e diferenciações sociais.

A intensidade do tempo, duração e programação na aquisição dessas qualidades, bem como a prática, conservação e manutenção do uso dos bens culturais, tornam-se essenciais na diferenciação das classes sociais. A outra face desta questão é que os estilos e marcas diferentes de roupas, de produtos da moda, de leituras, de alimentos, de habitações, de lazer, além de uma série de outros artefatos consumidos, muito embora sejam passíveis de mudanças, imitações e cópias, constituem um conjunto de indícios utilizados no ato de classificar e hierarquizar os outros. Assim, para a análise dos estilos de vida é importante lançar mão do pensamento de Bourdieu (1979) sobre a distinção, que aponta as preferências por certos bens culturais como marcadores de classe e para o princípio estruturante básico do mapa da estrutura de classes, que consiste no volume de capital cultural e econômico detido pelos grupos.

No entanto, particularmente no contexto atual, a oferta de novas mercadorias é intensa e múltipla, também é grande a incidência de usurpação dos bens marcadores por grupos de mais baixo status, provocando deste modo uma certa banalização de conjuntos de bens. Tal fato produz um efeito de perseguição infinita por diferenciação, segundo a qual "os de cima serão obrigados a investir em novos bens a fim de restabelecer a distância social original" (Featherstone, 1995, p. 38). Em outros termos, sob o prisma da distinção, o que rege a apropriação dos bens não é a satisfação das necessidades, mas a escassez desses bens e da impossibilidade de que outros os possuam.

Por fim, é preciso considerar possíveis limitações ao arsenal teórico de Bourdieu: a oferta excessiva e variada de bens de consumo, no contexto atual, "a fermentação e a desordem culturais, tão decantadas e muitas vezes rotuladas de pós-modernismo" (Featherstone, 1995, p. 40), a dispersão dos signos e a dificuldade de estabelecer códigos estáveis e compartilhados podem remeter a dificuldades adicionais para o conhecimento, hierarquização e escolha dos bens mais diferenciadores no interior de um determinado grupo de status; podem, no limite, embaralhar e deformar habitus, diminuindo a importância do gosto e dos estilos de vida. Mas também é possível que na desordem, decorrente de afrouxamentos de controles no campo cultural, existam princípios hierarquizadores embutidos mais profundamente, é possível inclusive deduzirmos que existam regras - e acreditamos que existem - na aparente desordem.

\section{Consumo e globalização}

Como já afirmáramos no contexto da globalização, a discussão sobre o consumo ganha um novo dinamismo, no pensamento social. A "acumulação flexível", termo cunhado por Harvey (1994), que bem caracteriza o arranjo capitalista atual, apóia-se na flexibilidade dos processos de trabalho, dos mercados, dos produtos e também dos padrões de consumo. Novas e mais rápidas linhas de mercadorias são abertas, o que significa a construção de novos desejos, necessidades, lançando reflexos de insegurança nos atores envolvidos em diversos níveis. Conforme Harvey (1994), “... massas de capital e de trabalho vão sendo transferidas entre linhas de produção, deixando setores inteiros devastados, enquanto o fluxo perpétuo de desejos, gostos e necessidades do consumidor se torna um foco permanente de incerteza e de luta" (p. 103).

Além da moda em mercados de massa - de roupas, ornamentos, decoração, atividades de recreação, esportes, música, jogos, produtos infantis, dentre outros -, os serviços disponíveis também deram uma contribuição inestimável ao incremento do consumo. No último caso, podem-se citar os serviços culturais, educacionais, de informação, esportivos e até de especialistas, que acabam por enfrentar o problema de gerar uma demanda que dê conta da oferta que podem disponibilizar no mercado (Bauman, 1999).

O campo da produção do conhecimento também não se apresenta imune a esta dinâmica. A leitura apressada do último lançamento, o imediatismo das pesquisas que se sucedem, o aligeiramento dos cursos, a formação de mais alunos em menos tempo, podem ser consideradas como práticas que advém da lógica consumista, reduzindo um tempo de convivência, um campo coletivo de criação - com o texto, o tema, os colegas e professores - necessário para que o "circuito de ressonâncias do pensamento possa se instaurar" (Caiafa, 2001, p. 196).

Desse modo, não se compram apenas mercadorias. Buscar avidamente novos modelos e "receitas de vida" também se constituem num tipo de compra.

Vamos às compras pelas habilidades necessárias a nosso sustento e pelos meios de convencer nossos possíveis empregadores de que as temos; pelo tipo de imagem que gostaríamos de vestir e por modos de fazer com que os outros acreditem que somos o que vestimos; por maneiras de fazer novos amigos que queremos e de nos desfazer dos que não mais queremos; pelos meios de extrair mais satisfação do amor e pelos meios de evitar nossa 'dependência' do parceiro amado...(Bauman, 2001, p. 88) ${ }^{3}$.

Os efeitos dessa dinâmica consumista são múltiplos, cabendo destaque a dois aspectos. Primeiro, a acentuação da velocidade, da volatilidade e efemeridade de produtos, modos, técnicas de produção e também de idéias, valores, ideologias, práticas e relações sociais; a fluidez ou "liquidez" - 
conforme Bauman (2001) - seriam as metáforas adequadas para captar a natureza não só do consumo, mas da presente fase da história dos homens. Mesmo um produto socialmente aceito deve "sustentar" sua utilidade, diante de novos desafios competitivos e “... novas 'utilidades' devem ser criadas para abrir espaço a novos produtos especializados ainda não oferecidos" (Bauman, 1999, p. 234). Muito mais do que a durabilidade e a confiabilidade do produto, hoje, o que traria lucro seriam a velocidade atordoante da circulação, o rápido envelhecimento do novo, a reciclagem, a substituição do "entulho". Em segundo lugar, as pessoas são forçadas a lidar com a idéia de descartabilidade, de obsolescência programada e sua satisfação enquanto consumidor deve ser instantânea. Vêem-se, assim, diante da perspectiva de conquistas de curto tempo, de golpear, permanentemente, suas experiências cotidianas, de "deletar" valores, estilos de vida, modos adquiridos de agir, relacionamentos estáveis e planejamentos de longo prazo, constituindo o que Jameson (1985) denominou de "mentalidade esquizofrênica". Sob este último aspecto, consumir significaria aderir a um presente raso e sem densidade; significaria "superar" - expressão da moda as reatualizações do passado e as transformações potenciais do futuro, em prol de um presente instituído.

Pode-se afirmar, portanto, que a estética relativamente estável do modernismo (do fordismo) - marcada por um conformismo cultural e um consumo de massa -, cede espaço a um novo dinamismo, no qual a capacidade técnica de produção, a proliferação das mercadorias e a fragmentação crescente do mercado, induzem à instabilidade, à velocidade que Sevcenko (2001) comparou ao "loop" da montanha-russa - e às qualidades fugidias de uma estética pós-moderna. Nos tempos globais, comemora-se a diferença, a efemeridade, a moda, uma maior mercadificação de formas culturais e uma pluralidade de sentidos e significados.

Considerando precisamente a insatisfação provocada pelo fluxo errático dos significados, Canclini (1999) e Bauman (2001), partindo de análises com suportes empíricos distintos, chamam a atenção para o fato de que o consumo poderia ser analisado como uma forma de tornar mais inteligível um mundo onde o sólido se evapora. Assim, adquirir objetos, organizá-los pela casa ou no próprio corpo, dar-lhes um lugar em uma ordem, designar-lhes atributos passíveis de estabelecer uma comunicação com os outros, são os recursos para se pensar a instável ordem social e as interações incertas com os demais. "A compulsão-transformada-em-vício de comprar é uma luta morro acima contra a incerteza aguda e enervante e contra um sentimento de insegurança incômodo e estupidificante" (Bauman, 2001, p. 95), que parece trazer, pelo menos, uma promessa de segurança, para os incertos caminhos da identidade pós-moderna. "Ir às compras" poderia significar, assim, um certo grau de liberdade para se selecionar a própria identidade ou uma tentativa de tornar mais lento o seu fluxo de mudança, ou ainda de solidificar o fluido ou dar forma ao disforme.

Outros autores, considerando a radicalidade das mudanças atuais - a aceleração tecnológica, a multiplicação das mercadorias, a fragmentação dos mercados, dentre outras - radicalizam o raciocínio da "liberdade no consumo" e destacam a existência de possibilidades de escolhas por parte dos consumidores. As coleções da moda - para ficarmos numa ponta bastante visível das mudanças do consumo nos últimos 30 anos - podem ser, no comentário de Joffily (2001), “... sérias, bem-humoradas, andróginas, ligeiras, descontraídas, glamourosas, libertinas, esportivas e mesmo clássicas, configurando, de algum modo, a possibilidade de diluição das fronteiras em diversos campos da contemporaneidade (espaço, tempo, gênero e classe)" (p. 168).

Assim, as modas seriam produzidas rapidamente e negadas no momento seguinte, exigindo dos envolvidos uma participação mais ativa na escolha. Ao mesmo tempo, a uniformidade se diluiria, abrindo espaço a uma cultura pós-moderna, não hierarquizável em divisões sociais fixas.

Featherstone $(1995,1999)$ é um dos autores que chamam atenção para este aspecto, mas sua originalidade reside justamente na tentativa de superar a polarização que vem atravessando todo este texto. Ele desenvolve uma perspectiva teórica de análise

capaz de ir além da concepção de que o estilo de vida e o consumo são produtos totalmente manipulados de uma sociedade de massas, bem como do ponto de vista oposto, que procura preservar o campo dos estilos de vida e do consumo (...) como um espaço lúdico e autônomo, além da determinação (Featherstone, 1995, p. 120).

Primeiramente, sugere que as práticas de consumo, seu planejamento, a exibição dos bens e a sua compra - as experiências que cercam o consumo no cotidiano - não podem ser analisadas somente mediante concepções de valor de troca e de cálculo instrumental e relacionado ao pólo capital ${ }^{4}$. O homem da cultura de consumo não adota um estilo de vida de maneira absolutamente irrefletida ou manipulada pela propaganda, há uma participação ativa do consumidor na composição de um estilo, manifesta pelos bens, práticas, experiências e aparências que exibe. Em sua própria expressão, ao se analisar as práticas de consumo, "as dimensões instrumental e expressiva não deveriam ser vistas como polaridades excludentes: antes, é possível imaginar que a cultura de consumo põe ambas em confronto numa balança" (p. 123).

Em segundo lugar, Featherstone (1995) destaca a insuficiência em se mapear os estilos e gostos com base na renda apenas, pois isso deixa escapar outros princípios de funcionamento e ordenamento das práticas de consumo. É bem o caso do conceito de capital cultural, cuja posse possibilita a conversão em poder social, independente da renda ou do dinheiro. O campo da cultura possuiria lógica e moeda próprias. Desse modo, propõe que se leve em consideração a existência de posições intermediárias entre a "alta cultura" e a "baixa cultura" (ou entre aquelas classes que possuem muito capital cultural e econômico e as que possuem pouco), dada a complexidade do espaço social.

Um último argumento central de Featherstone - baseado em Bourdieu - é que a nova concepção de estilo de vida pode ser mais bem compreendida se relacionada ao habitus ${ }^{5}$ das frações de classe. Em outros termos, recomenda que para 
uma consideração das preferências de estilo é preciso examinar a economia dos bens culturais (Bourdieu \& Passeron, 1975) num espaço social estruturado, "no qual vários grupos, classes e frações de classe lutam e competem para impor seus gostos específicos" (Featherstone, 1995, p. 124).

Sob outra perspectiva de análise, Canclini (1999) chega a conclusões semelhantes quanto à interação do consumidor com a mercadoria: “o desejo de possuir 'o novo' não atua como algo irracional ou independente da cultura coletiva a que se pertence" (p. 84); os contextos familiares, de bairro e de trabalho também controlam o consumo, os desvios nos gostos, nos gastos e a seleção do "exógeno". Para tais autores, portanto, a crítica ao consumo como lugar irrefletido e de gastos inúteis deve ser revista.

Os elos que unem as pessoas àquilo que consomem são, portanto, complexos. O capital - cultural, simbólico e financeiro - empenhado em vestuário, ornamentos decorativos e objetos pessoais, recursos e o tempo aplicados no aperfeiçoamento da educação, do corpo e até das habilidades de expressão ${ }^{6}$ são múltiplos. Para muitos homens e mulheres, por exemplo, o consumo privado de bens quase que se constitui no seu estatuto de cidadania, o que vem permitindo a alguns autores (Canclini, 1999, por exemplo) a redefinir o conceito de consumo, ultrapassando o cenário de gastos inúteis e impulsos irracionais para a idéia de que a noção política de cidadania estaria se expandindo "ao incluir direitos de habitação, saúde, educação e a apropriação de outros bens em processos de consumo" (Canclini, 1999, p. 14).

No entanto, nesta pluralidade de "processos de consumo", não se pode deixar de considerar dois aspectos. Primeiro, que o capitalismo ao criar acessos cada vez mais amplos e diversificados, também faz valer as suas "regras" em um maior número de domínios, em campos mais moleculares e mais íntimos, de modo que o fato de comportar uma grande quantidade de modelos de realização, não exclui a submissão ao seu axioma central: mais produtividade e mais consumo. $\mathrm{O}$ segundo aspecto a relevar é o seguinte: enquanto para alguns se trata da análise do porquê consomem e consomem tanto, para "mais de um bilhão de pessoas consumir mais é uma questão de vida ou morte e um direito básico - o direito de libertar-se da carência" (Gordimer, 2000). Em outros termos há muitos que ficam fora deste universo de estudo denominado consumo, o que evidentemente tem grande efeito tanto sobre os que ficam de fora, quanto sobre os que estão dentro.

Nesta relação entre os de fora e os de dentro, é preciso estar alerta para alguns raciocínios, que culpam os próprios alijados do consumo de sua "má sorte". Uma argumentação bastante comum é a do desperdício do dinheiro usado no consumo popular, uma espécie de auto-sabotagem ou mesmo ignorância dos pobres, que assim demonstrariam sua incapacidade para se organizar e progredir. Outra argumentação bastante recorrente é a de que quem tem menos poder de compra e negociação, inexoravelmente empurrado para as margens ou para fora do sistema, é uma "vítima de sua própria falta de iniciativa, incapacidade produtiva ou inadaptabilidade à vida moderna" (Sevcenko, 2001, p. 48). De todo modo, nos dois casos, a responsabilidade pelo "fracasso" cai principalmente sobre os ombros dos "fracassados".

Este tipo de avaliação preconceituosa, na realidade, pode ser atribuída à atitude presentista - já apresentada anteriormente - e que neste caso consiste em fazer "tábula rasa" das circunstâncias históricas, sociais, econômicas, culturais, dentre outras, que favoreceram pessoas, comunidades, grupos e populações a situações desiguais, diversas e hierarquicamente arranjadas.

\section{Considerações Finais}

Apesar do intuito deste trabalho ter sido o de traçar historicamente, os percursos teóricos sobre o consumo, não existe a pretensão de se finalizar tal traçado, posto que, o mote das discussões aqui apresentadas, pode ser localizável, de maneira significativa, na pauta de muitos intelectuais, críticos e debatedores de todos os continentes. Como vimos, muitas hipóteses são levantadas para os intercâmbios feitos pelos homens: consumimos para satisfazer necessidades fixadas culturalmente, para nos distinguirmos dos demais, para realizar desejos, para fixar nossa posição no mundo, para controlar o fluxo errático dos significados, para obter certa constância ou segurança, para ampliar a tão rebaixada cidadania. São complexos, portanto, os destinos contemporâneos das mercadorias, ao menos sob a pena dos analisadores teóricos e pesquisadores.

De fato, a temática do consumo e da cultura de consumo nunca foi tão analisada como nos dias que correm, localizando-se no embricamento das discussões culturais e econômicas, políticas, sociais e psicológicas, no entanto, da indústria do entretenimento ao consumo estético da mercadoria, seja por sua imagem, por sua utilidade imediata, pelas emoções que desperta ou ainda, pelas diferenciações que pode proporcionar às diversas tribos de consumidores, ainda se fazem necessárias muitas pesquisas e análises.

Para finalizar, nesse percurso de tantos autores, sobressaíram duas advertências para o prosseguimento dos estudos. A primeira refere-se à impossibilidade da análise de tal temática em si, desvinculada de suas múltiplas tangências, com aspectos econômicos, políticos, históricos, sociais, culturais e psicológicos. Por fim, é preciso não ceder à força das teorias. Se elas são importantes ferramentas para se pensar a complexidade do social - no qual o consumo dispõe de peso significativo - é preciso o recurso ao exame empírico, em espaços sociais concretos e a capacidade de se deixar surpreender com as contingências que as investigações possam oferecer.

\section{Referências}

Adorno, T. W., \& Horkheimer, M. (1990). A indústria cultural: o Iluminismo como mistificador de massas. In L. C. Lima (Org.), Teorias da Cultura de Massa (5 $5^{\underline{a}}$ ed., pp. 169-214 ). São Paulo: Paz e Terra (Obra original em alemão publicada em 1947).

Baudrillard, J. (1985). À sombra das maiorias silenciosas: o fim do social e o surgimento das massas. São Paulo: Brasiliense. 
Baudrillard, J. (1995). A sociedade de consumo. Rio de Janeiro: Elfos Editora; Lisboa: Edições 70.

Bauman, Z. (1999). Modernidade e ambivalência. Rio de Janeiro: Jorge Zahar. Bauman, Z. (2001). Modernidade líquida. Rio de Janeiro: Jorge Zahar.

Bourdieu, P. (1974). A economia das trocas simbólicas. São Paulo: Perspectiva. Bourdieu, P. \& Passeron, J. C. (1975). A reprodução. Rio de Janeiro: Francisco Alves. Bourdieu, P. (1979). La distinction: critique social du jugement. Paris: Edition de Minuit.

Caiafa, J. (2001). Arte, técnica e poderes. In N. Villaça \& F. Góes (Orgs.), Nas fronteiras do contemporâneo (pp.193-200). Rio de Janeiro: Mauad/FUJB.

Canclini, N. G. (1999). Consumidores e cidadãos: conflitos multiculturais da globalização. (4 ${ }^{\mathrm{a}}$ ed.). Rio de Janeiro: Editora UFRJ.

Certeau, M. (2000). A invenção do cotidiano: artes de fazer ( $5^{\underline{a}}$ ed.). Petrópolis: Vozes.

Featherstone, M. (1995). Cultura de consumo e pós-modernismo. São Paulo: Studio Nobel.

Featherstone, M. (Org.) (1999). Cultura global: nacionalismo, globalização e modernidade. ( $5^{\mathrm{a}}$ ed.). Petrópolis: Vozes.

Giddens, A. (1993). A transformação da intimidade: sexualidade, amor e erotismo nas sociedades modernas. São Paulo: Editora da Universidade Estadual Paulista.
Gordimer, N. (2000, 20 de fevereiro). A face humana da globalização. Folha de São Paulo, Caderno Mais, pp. 6-8.

Jameson, F. (1985). Pós-modernismo e sociedade de consumo. Novos Estudos CEBRAP, 12, 16-26.

Joffily, R. (2001). Sobre o vestuário feminino: da regra à indefinição. In N. Villaça \& F. Góes (Orgs.), Nas fronteiras do contemporâneo (pp.166-171). Rio de Janeiro: Mauad/FUJB.

Harvey, D. (1994). Condição pós-moderna: uma pesquisa sobre as origens da mudança social. ( $2^{-}$ed.). São Paulo: Loyola.

Marcuse, H. (1968). A ideologia da sociedade industrial. Rio de Janeiro: Jorge Zahar.

Marx, K. (1980). O Capital (Livro 1, v. 1). Rio de Janeiro: Civilização Brasileira (Obra original em alemão publicada em 1867).

Rocha, E. (1995). A sociedade do sonho: comunicação, cultura e consumo ( $2^{\mathrm{a}}$ ed.). Rio de Janeiro: Mauad.

Sevcenko, N. (2001). A corrida para o século 21. São Paulo: Companhia das Letras.

\section{Nota}

1 A data inicial, simbólica, do início do fordismo é 1914, quando Henry Ford implantou modificações na linha de montagem de carros que estabelecera em Michigan.

2 Dois textos de Baudrillard foram utilizados neste trabalho "A sociedade de consumo", edição em português de 1995, mas cujo original é de 1970, e "À sombra das maiorias silenciosas: o fim do social e o surgimento das massas", escrito na década de 80. Nesta última obra, marcada pelo contexto da globalização, a teorização de Baudrillard (1985) é radicalizada de modo a assumir que vivemos num mundo simulacional, no qual a distinção entre real e imaginário esvaiu-se em direção a uma cultura baseada numa profusão de imagens e informações, não estabilizáveis, que estaria sugerindo também a irrelevância das divisões sociais fixas e, em última análise, o fim do social enquanto referência de importância.

3 Sob este aspecto, as análises de Bauman (2001), se contrapõem às de Giddens (1993) para quem o "sexo de plástico", os "amores múltiplos" e as "relações puras" comportariam efeitos emancipadores, de autonomia individual e a liberdade de escolha.

4 Na realidade, o próprio neomarxismo se afastou da visão das mercadorias como meras utilidades possuidoras de valor de uso e de troca, como é o caso de Baudrillard discutido anteriormente.

5 O conceito de habitus remete às disposições inconscientes ou não, a esquemas classificatórios, a redes de preferências que o indivíduo possui e que lhe transmite a impressão de adequação e validade de seu próprio gosto por certas práticas e bens culturais.

6 Tal consideração, aliada à análise da aceleração das mudanças a que os produtos estão submetidos, em consonância com o ritmo célere das inovações tecnológicas, têm levado alguns autores (Certeau, 2000; Sevcenko, 2001) à consideração da ampliação do papel da visão como fonte de "orientação e interpretação rápida dos fluxos e das criaturas, humanas e mecânicas, (... provocando) uma profunda mudança na sensibilidade e nas formas de percepção sensorial das populações metropolitanas” (Sevcenko, 2001, p. 64).

Deise Mancebo, doutora em História da Educação pela Pontifícia Universidade Católica de São Paulo, é Professora Titular e Pesquisadora do Programa de Pós-graduação em Psicologia Social da Universidade do Estado do Rio de Janeiro, RJ.

Dayse Marie Oliveira é estudante de Psicologia da Universidade do Estado do Rio de Janeiro, bolsista CNPq. Jorge Guilherme Teixeira da Fonseca é estudante de Psicologia da Universidade do Estado do Rio de Janeiro, bolsista FAPERJ.

Luciana Vanzan da Silva é estudante de Psicologia da Universidade do Estado do Rio de Janeiro, bolsista FAPERJ.

Endereço para correspondência: Deise Mancebo, Rua Barão de Cotegipe 416 casa 7, Vila Isabel, 20560-080, Rio de Janeiro, Fone: (21)2577.4196. E-mail: mancebo@uerj.br. 